http://www.jfas.info

\title{
REALIZATION OF PEACE FROM THE PERSPECTIVE OF THE ROLE OF HIGHER EDUCATION IN THE FIELD OF DIPLOMACY: EXPERIENCE OF ACADEMIC DIPLOMACY IN IRAN
}

\author{
M. Zakerian ${ }^{1}$, Z. Sadoughi ${ }^{2}$, A. Nabavi $^{3}$, R. Mahdi ${ }^{3}$ \\ ${ }^{1}$ Assistant professor in Faculty of Law and Political Sciences, Islamic Azad University \\ ${ }^{2}$ Department of Cultural Policy Making at the institute for Social and Cultural Studies, \\ Tehran, Iran \\ ${ }^{3}$ Institute for Social and Cultural Studies, Tehran, Iran
}

Published online: 15 February 2017

\begin{abstract}
New diplomacy with a focus on new actors is a ground for removal of misconceptions and solution of conflicts through communication, dialogue and reach of consensus. Higher education institution, especially universities, can be referred as new actors in the field of diplomacy. They can play an important role in communicating mutually and symmetrically. According to the authors, universities can provide the ground for removal of misunderstanding which is the root of violence at the level of communication within universities, both in a form of diplomacy Track II and also, through playing role in the science and technology diplomacy framework and they can be effective in promoting the culture of peace while they present positive image and enhance the country's position in the international arena. So, in present study, it was tried to analyze the promotion of culture of peace in terms of the effectiveness of higher education on diplomacy institution and also, the position of higher education institution in the diplomacy of the Islamic Republic of Iran by descriptive-analytical method and relying on the Habermas's communicative action theory.
\end{abstract}

Author Correspondence, e-mail: z.sadoghi@iscs.ac.ir

doi: http://dx.doi.org/10.4314/jfas.v9i1s.686 
The results showed that the universities can contribute to the realization and promotion of peace through affecting diplomacy and relying on science and knowledge which are international language; also provided that there is purposeful policy-making to maximum use of the potential of higher education institutions in general, and specifically universities. Especially in Iran, despite negative beliefs, universities can provide positive images in international arena.

Key words: higher education, university, peace, science diplomacy, diplomacy Track II.

\section{INTRODUCTION}

Establishment of peace and rejection of violence have been always of the concerns of human that it has become a pretext for the actions of many social and religious movements in recent centuries. In the new millennium, in addition to changes in different security, social, cultural and political procedures at national and international levels due to globalization, establishment, maintenance and promotion of peace have been considered more than before. In fact, globalization, beyond local and national issues confronting human, has caused a number of problems in the international arena. These problems are not limited to a specific community and are shared concerns of all human beings and also, can be obstacles to peace. Thus, the collective will to resolve global issues and establishing a culture of peace to replace the culture of violence and extremism and achieving sustainable development are the priorities of policy making for many governments and organizations and they have led to various proposals an actions. By considering a culture of peace as a target, applying all methods and actors by governments is inevitable. Among them, the role of diplomacy institution in establishing and promoting peace can be noted.

In the globalization era, parallel to the developments created in various fields, diplomacy has become more interactive and conversation-based and various forms of diplomacy have been formed in order to meet current needs with a focus on new actors. In fact, the governments meet all the requirements and global objectives alone and this made the entry of new actors to the field of diplomacy necessary. These actors play an important role from the stage of decision-making and policy-making to the implementation of programs. This is that today, the entry of NGOs, media, various institutions and even individuals in to field of diplomacy and development of modern diplomacies can be seen; public, cultural, academic and science and technology and other types of diplomacies are the examples of changes in traditional diplomacy. 
With this introduction in present study, the role of higher education institution and university in establishing peace through influencing the country's diplomacy institution was investigated by referring to the necessity of modern policies and the roles of new actors in establishing peace, stability and security in the world. The authors have tries to answer the following key question: what role do higher education in general and specially university, as an active actor, play in establishing peace in the field of foreign policy through influencing diplomacy institution? In examining the function through descriptive-analytical method, following hypothesis was tested: university, as a rational actor in the field of diplomacy, beyond the educational and research functions, plays an important role in achieving common understanding, eliminating misconceptions and creating peace dialogue and this can minimize the stress and establish peaceful relations in foreign policy. For these purposes, university is a place for exchanges between university professors and students, a venue for dialogue between academic communities, and also, a place for scientific activities that in the last option, university can be examined as an active actor in the area of science and technology diplomacy. It is not possible except by relying on research on peace conducted at universities and other research centers and training how to talk.

\section{Theoretical and research background}

In the current period, realization of goals and resolution of concerns are possible in the shadow of coordination and cooperation and all of them are provided in the light of peaceful and conversation-based space. In this context, "Thomas Risse" believes that conversation is a form of social action that affects the process of global politics and diplomacy and so, the actions performed in the global arena can be known on the basis of conversation (Risse, 2000). So, in contrast to the theories such as realism which emphasize on the wickedness of human nature and analyze the negotiations in terms of power and interests (Moshirzadeh, 2005); Habermas's communicative action theory, which is based on conservation, communication and rationality, is invoked.

"Jürgen Habermas" has an optimism look at human emancipation in the light of communication and conversation. So he suggests "communicative action theory" from this perspective. Communicative action is a social action aimed at achieving understanding (Bolton, 2014). He knows communicative action between humans in the social world as the factor of unity, solidarity and human emancipation and emphasizes on the formation of an order under which all people can talk together on equal terms (Griffiths, 2009). According to Habermas, common understanding through reasoning, consensus and cooperating with each other and he suggest communicative action theory to prove that social conflicts should be 
ideally resolved without violence. For this purpose, a social system must be fulfilled where decisions are made and implemented in the form of an argument (Mahdavi and Mobaraki, 2006). The main focus of Habermas's most of works and thoughts is to portray a better global society in which universal understanding, peace and equality, solidarity and prosperity are provided for all human beings. In his view, the premier community that he is trying to portray it, is more rational society; it is a society based on rationalism, peace, unity and in compliance with the collective needs (Mir, 2007).

Generally, Habermas classifies the human actions into two categories as follows:

- An action aimed at success: this type of action is taken in advance with the motivation of calculated pursuit of self-interest (Riterz, 2009).

According to Hubernas, this type of action has two types:

- Tool action: refers to actors who choose the most suitable tools in a reasonable and pragmatic way to achieve a target.

- Strategic action: refers to the action of two or more people who coordinate their reasonable and purposeful action in pursuit of a target (Riterz, 2009).

- An action aimed at understanding and logical reasoning or communicative action which is the interest to present study. It is assumed that people understand and want to advance their goals through dialogue and listen to each other. In this form of action, dialogue occurs in equal, open space without coercion and away from the power relations (Jonstone, 2003) and rationality and reasoning are the center of action. Habermas says that only those who are able to communicate, can establish communicative action (Hadian and Saeidi, 2013).

So, when the conservation is mentioned as a way of mutual understanding and establishing peace, Habermas's communicative action theory provides an elaborate framework. In the theory, symmetrical conversation is centered. In fact, the actions of the various actors are coordinated through the exchange of communicative actions and language (Fitzpatrick, 2011). Habermas's emphasis on communicative action can be applied as a model for establishing reconciliation and peace in international relations in the form of diplomacy. In fact, it is assumed that since in Habermas's communicative action theory, some characteristics are considered for action and conversation among actors (open and free space for dialogue, dialogue based on respect for and recognition of multiple identities), it, in the form of diplomacy, can provide the ground to fix misconceptions and also, it can result in mutual understanding. 
From a macro perspective, diplomacy means the communication process between international actors who want to resolve disputes without tension and violence through negotiations. So, diplomacy is associated with the efforts to manage and create order within a global system and its aim is to prevent conflict from turning into war. But at the micro level, diplomacy can be seen as a political instrument that international actors use it to conduct foreign policy so that they can achieve their political goals (Bilis and Smith, 2004). Diplomacy, as the art of communication and dialogue to solve problems and fulfillment of needs, has existed from the beginning of human history and in particular, it is seen very important and necessary in the international relations and negotiation between two people or two nations and governments. Diplomacy prevents war and violence and strengthens the ties between the two nations. Therefore, it is believed that without a strong and efficient diplomacy, many global affairs remain to be resolved, there won't be other international organizations and above all, the permanent war will be going on in the world (Amacker, 2011).

As mentioned, the developments of the 20th century has led diplomacy to a new era in a way that beyond traditional diplomacy, new forms of diplomacy can be seen in the field of foreign policy. It is noted that diplomacy is divided into three groups in terms of the nature of the actors involved in it:

- Government-to-government diplomacy (official diplomacy)

- Government-to-people diplomacy (public diplomacy)

- People-to-people diplomacy (diplomacy Track II) (Hadian and Saeidi, 2013).

Political and government officials can be highly effective in the pursuit of national interests by relying on a lot of resources at their disposal. Today, changing conditions in the international arena has led the government to resort to other means in addition to formal negotiations in order to supply the interests. Especially, the development of new technologies and the emergence of new actors in the international arena have followed development of diplomacy and the need to use the capacity of other actors in pursuit of goals is felt more than ever. Due to this, beyond government-to-government diplomacy, formation of new forms of diplomacy can be seen, government-to- people diplomacy and people-to-people diplomacy are the new forms of changes in the field of diplomacy. In particular, using Habermas's theory on open and power relations-free dialogue space, the importance of role of new actors as a way to reach peach becomes obvious more than ever. One of the new actors in the field of diplomacy that can play an effective role in promoting national and international peace is university. It is an institution that can be paid attention due to its capacity in production and 
transfer of knowledge and also as a framework for consultation and dialogue between elites and scientists.

The role of universities in the field of diplomacy has been paid attention in terms of academic exchanges in the form of diplomacy Track II, in terms of academic debates and discussions in the form of science and technology diplomacy and in terms of the capacity of universities in developing knowledge, in training diplomats, in producing the literature related to diplomacy and peace and also teaching dialogue through creating open space for debate and discussion. Traditionally, education and research are considered as the most important functions of the university. In the past, many universities had more impact on the promotion of culture of violence that this impact can be examined in the form of complicity in the best mode and in the form of participation in the worst mode. In addition to military universities in which war was taught, war techniques were also taught in many non-military universities. Also, universities were the place for the production on knowledge about war and violence through performing research. But, today, the values associated with positive peace such as respect, tolerance, responsibility and toleration are important, the role of university and education, especially in the context of academic education, has been emphasized as a tool helping people to choose their individual options (based on their judgment) better while expressing smart satisfaction to collective behavior (Gauff, 2007).

In the university, individuals are taught how to talk to people through the programs followed by the university as well as specific content provided by the universities, during this training, people accept to respect for the opinions of others and understand that they are responsible to themselves and society and nature, so, they can be promoter of peace and friendship and behave in individual and even international relations based on justice and respect. Training peace is a promotion of global pure consciousness vision that enables all people to act as global citizens (Reardon, 1988). Even diplomats engaged in official negotiations are trained in the university and learn how to negotiate in the best way to maximize national interests, how to listen to other side well, and how to resolve disputes in a peaceful manner as much as possible. Academics can produce scientific context and knowledge in order to help the formation of new paradigm with a focus on peace, dialogue, cooperation, tolerance and responsibility. Also, universities also be able to adopt the measures such as holding courses such as crisis simulation models and simulation of the United Nations, to promote a culture of peace in addition to informing students. But the greatest effectiveness of academic diplomacy can be examined within the framework of diplomacy Track II and academic diplomacy based on scientific debate. In particular, using the potential of science and technology is placed 
within the framework of what called "soft power" by Josef Nye (Nye, 1990). In diplomacy Track II, academic exchanges and communications are considered to normalize relations and in academic diplomacy, scientific debate and discussion are paid attention (Zakerian, 2016). In the form of diplomacy Track II, the relations among academics of various countries can be effective in providing positive image and enhancing the prestige of a country at international level. This is a goal emphasized more in new diplomacies. Here, diplomacy is characterized by three functions:

- Relation-building: it means establishing long-term communication with people of foreign communities in order to identify a country to them and create a sense of community, its people and values in the mind of foreign audiences through providing the ground of mutual understanding.

- Image Management: management of a country's image in the international arena and representations of faces and positive image of the country.

- Accreditation: increasing the credibility among foreign communities that enhance the legitimacy of government actions at the international level (Hadian and Saeidi, 2013).

That is why that today, in many universities throughout the world, international affairs office or department has responsibility for these relations and communications and it tries to follow the interests within these communication and relations through the adoption of applications for sending and acceptance of students and teachers, holding joint training and research courses, science camps, holding seminars and international conferences, holding exhibitions and etc. What is important is that the mere communication is not enough, this communication should be purposeful. That is why that the policy of internationalization of universities has been emphasized in recent years. Internationalization is "the process of global, intercultural and international integration in line with the objectives and functions of education after high school» (Knight, 2008). A set of activities related to development of international cooperation and scientific and academic relations with the aim of providing education and research settings in the universities which are really connected and correlated with global prospects and advancements, are called internationalization (Fazeli, 2004). Internationalization of higher education is a central concept that requires specific academic structures, including management, curriculum and purposeful academic programs. In the policies and programs of internationalization of universities, two levels can be raised: one, internationalization of universities at the international level which include the exchanges of individuals. Here, academic exchanges can lead to being familiar with the culture of other side and also eliminate the institutionalized misunderstandings and result in lasting peace. Two, 
internationalization at national level which is based on the curriculum and measures in the line with the development of international understanding and intercultural skills (deWit \& et al, 2015).

Scientific debates between universities and activities of universities in the field of science and technology is another aspect in the investigation of role of universities in the field of diplomacy. In this sense, academic diplomacy approaches to science and technology diplomacy. Science and technology diplomacy is a new concept in the field of international relations and its main issue is to use the capacity of science and technology in order to achieve the objectives of foreign policy. Science diplomacy is the use of scientific tool in the interaction between countries to solve common problems faced by humanity and to create international knowledge-based cooperation (Federoff, 2010). In a statement of the World Conference on Science in the 21st century: "scientific thinking is the ability to explore the issues in terms of different aspects and ...so, science is based on critical free thinking that is the essential foundation for democracy. The scientific community should always enhance the spiritual and moral solidarity which is the basis of culture of peace as mentioned in the documents of UNESCO with belief in the tradition which is beyond national, religious or ethnic affiliation. Collaboration of scientists around the world is considered as productive and precious participation in the creation of overall security and development of peaceful relations between different nations, societies and cultures" (World Conference on Science, 1999). In 2010, the American Association for the Advancement of Science defined three areas for science and technology diplomacy:

- Science and technology in diplomacy: it means that science works towards shaping and supporting the goals of foreign policy.

- Diplomacy for science and technology: in this case, diplomacy system facilitate the cooperation between science and technology.

- Science and technology for diplomacy: in this case, cooperation between science and technology improves international cooperation. This form of diplomacy can be investigated and evaluated in the framework of soft power (Vice-Presidency for Science and Technology, Presidency of the Islamic Republic of Iran, 2011).

Academic diplomacy seeks to develop and strengthen co-existence between the goals of foreign policy and scientific incentives (NAAAS, 2010). Science and technology cooperation between academics and scientific society influence the relations between countries at international level and help to strengthen the relations. Science is a type of universal language and can be used as a tool for communications between nations, it is a neutral language which 
is away from politics. Scientific values are rational, transparent and public, and are the same all over the world. These values can help build trust among nations and form the foundation for good governance (NAAAS, 2010). Science is a non-ideological environment for participation and free exchange of ideas between people regardless of cultural, national and religious. According to Kissinger, there is nothing more international than science (Turekian $\&$ Neureiter, 2012). So, science diplomacy is a tool for awareness of scientific achievements and advances in science and technology and also it is a way to advance the goals of foreign policy and to work with other governments.

After the world war II, due to the widespread use of chemical weapons, the linkage between science and technology has been paid attention and scientists have taken major efforts to reduce conflicts, so that in 1955, Bertrand Russell and Albert Einstein issued a statement and called scientists around the world- regardless of their political trends- to address the threat posed by nuclear weapons (NAAAS, 2010). Science creates a type of diplomacy that requires close cooperation among nations, elite, departments and NGOs in various countries. It would be optimistic to create and form regional and international alliances as the results of creation of common interests and resolution of conflicts among nations and peoples through scientific exchanges. What is important is that science must be produced that can be tested and verified in all parts of the world (Zakerian, 2016).

In general, university has great potential in forming conservation-based connections in a form of science diplomacy and diplomacy Track II according to its educational, research and social services functions and by relying on science and knowledge capital and scientific community and especially, during the cold political relations, it can be a context for communication and in the views of authors, Habermas's communicative action theory also provides an elaborate framework for this role. According to the action focused on understanding, university is an active actor in the field of diplomacy because in an equal, open space without any threats and coercion and away from power relations and based on rationality and arguments and by relying on the knowledge and science capital, it can provide the ground for a relationship based on conservation. If university is defined with the characteristics such as knowledgeorientation, emphasis on training analytical thinking, emphasis on making the knowledge public, research-orientation and training research skills, focusing on creative learning and open space (Shah Talebi, 2008), it can be a ground for conversation in the form of debates and discussion, liberal meetings and training communication in the form of academic programs and research in this field. Also, university and academic elite community can provide a positive image of a county and help to advance the goals of foreign policy in addition to 
participation in international activities and communities and being involved with other universities. So, in the 21 st century, university is the most important and common means of communication. This means that it uses both oral and written languages as a means for conservation and can play a key role in establishing peace and relieving tension. Figure 1 illustrates this effectiveness.

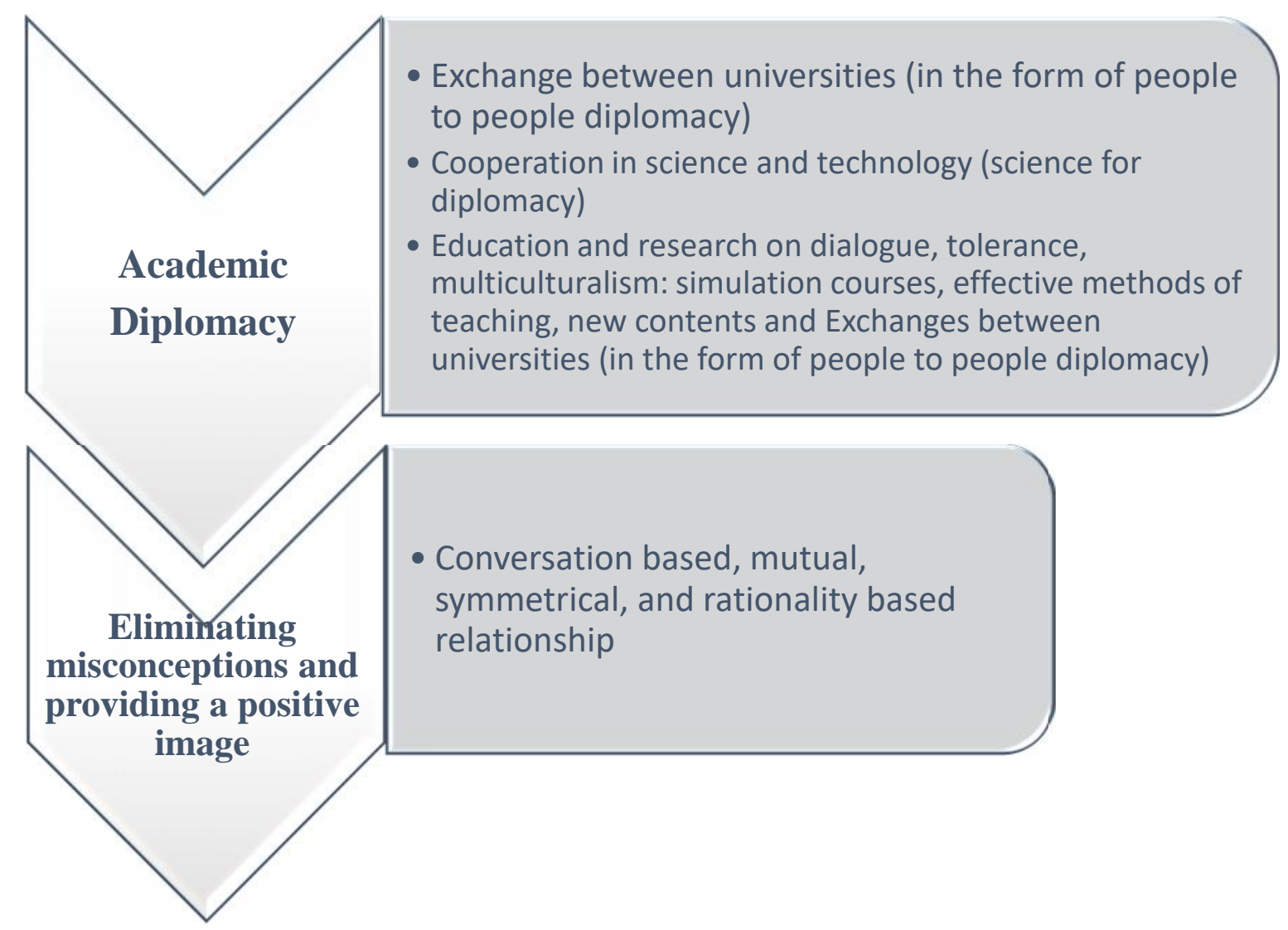

peace

Fig.1. The role of higher education institution in promoting a culture of peace through influencing diplomacy

Accordingly, it seems necessary that diplomacy system uses university in order to advance the foreign policy of any country. In Islamic Republic of Iran, in parallel to the increased international community's attention to academic diplomacy, the importance of the issue has been understood. In following, the role of higher education institution in the Islamic Republic of Iran's diplomacy will be examined.

\section{Method}


Present study consists of two sections of investigation of potential of higher education institution in promoting the culture of peace through influencing diplomacy and investigation of academic diplomacy in Iran. In terms of goal, present study is applied, in terms of data collection, it is library study and in terms of type of method, it is qualitative analytical. The data was firstly gathered through literature research and using archived documents and then, it was analyzed. Presents study aimed to investigate existing literature and experiences to identify challenges and obstacles in order to suggest solutions to make maximum use of higher education institution in promoting peace.

\section{Results}

One of the main topics of the sixth development plan of Iran is internationalization and globalization of universities and educational institutions (Sixth Development Plan, 2016). In recent years, the issue of internationalization of universities has been paid attention by the Ministry of Science and the universities have begun taking actions within the framework of the Department or the Office of International Affairs. For example, signing Memorandum of Understandings between universities towards sending and acceptance of professors and students between universities and holding joint courses. In fact, policymakers and academics have understood the importance of this interaction and its effectiveness in enhancing the legitimacy of Iran at international level. For various reasons, many countries don't look on Iran favorably and the concept such as violence, extremism, conflict, insecurity, terrorism are shaped along Iran in the minds. This negative images leads to mutual misunderstanding and violence, accordingly, academic elites, including professors and students, can play a significant role in changing mentalities by relying on their communicative ability and scientific skills and help to enhance the image of Iran in the international arena and provide the ground for conversation and defusing the tensions. In the past, Iran has experienced the discussion of internationalization at the "Jundishapour" University. The university is a place for gathering scholars of different countries and also it played an important role in international exchanges; so that on its main entrance, following sentence was written: "power of thought and pen is more than the sword" (Mahozi, 2016)."

But in the pursuit of the goal of internationalization of university, there are problems due to lack of purposeful programs and appropriate infrastructure. In Iran, in higher education system, Memorandum of Understandings have been signed between each of the universities and or the Ministry of Science and foreign universities and research centers. But many of Memorandum of Understandings have been not implemented and also, no solutions has been defined to implement them. Also, no required infrastructure has been considered in some 
universities; from the accommodation to educational facilities. In recent years, many attempts have been made for acceptance of non-Iranian professors and students but they have been not sufficient and in many universities, non-Iranian students engaged in minimal amenities, especially in the field of housing. One of the main indicators of internationalization of universities is to attract foreign students (Maringe \& Foskett, 2010). According to the statistics provided by the Ministry of Science (2015), in Iran, about 14800 non-Iranian students are studying are (Ministry of Science, Research and Technology, 2016). According to a study performed on non-Iranian students at Tehran University, Shahid Beheshti University, Imam Khomeini International University, Tarbiat Modarres University, Mashhad University of Medical Sciences in 2013-14, some students were complained of difficult environment, insecurity in the night, insecurity in the use of public transport, lack of communication, theft in the dormitory, criticizing the dress, inappropriate behavior of security officials and inappropriate behavior of staff (Yamani and Teimouri, 2015). This shows that the infrastructures required for acceptance of non-Iranian students have been not provided and due to this, academic interactions face with the problems. In the Iranian universities, the local structure consistent with local needs, long and wide bureaucracy, hierarchical management, lack of curriculum tailored to the international requirements, mismatch between current status of professors and internationalization of university are the obstacles to the internationalization of universities (Mahozi, 2016).

New educational technologies are the other structures needed to attract non-Iranian students. They are reflected in four sections of structure, management, curriculum and professors. In Iran, academic structures have been shaped based on local needs and requirements and they don't suit international structure. In terms of management, team and circular structure is suitable for handling international universities, but in Iranian universities, management structure is hierarchical and vertical. Also, internationalization demands special content and curriculum, the content and courses, especially in the humanities, are not defined in accordance with students' needs (Mahozi, 2016). Suitable curriculum in the international higher education should provide grounds and elements necessary to meet the needs of students who come from other countries and their aims, in line with the goals of international higher education, are to experience cultural items, to be familiar with the language of the host country and to introduce their cultures in addition to academic progress and on the other hand, it should provide the grounds and elements necessary to prepare domestic students to learn and experience in abroad educational settings (Aarefi, 2005). In terms of contents, also, in Iranian universities, establishing new disciplines has been not paid attention, the courses are 
not related to global developments and they are inattentive to global issues (such as poverty, peace, the environment, etc.) (Fathi and Ejargah, 2009).

About sending students abroad, some programs have been adopted so far. Students are sent abroad by the government, but there is no plan to take advantage of their potentials outside the country. They can play an important role in the intercultural conversation. These students are familiar with the culture of other countries, modern science and new technologies and these items can be considered as an opportunity for cooperation between universities.

About the special joint training and research courses, the Ministry of Science has taken steps so far. For example, it is noted in the documents of the Ministry of Science: "By virtue of clause (3) of paragraph (f) of the Fifth Development Plan and in order to enhance the academic standing of the country at the national, regional and international levels, to create active and coordinated communication between local and abroad universities and to achieve the first place in the region in terms of science and technology and to consolidate it by the end of the fifth development plan, universities and higher education and research institutions can take steps to plan, get the license and hold common educational courses with prestigious foreign universities and research centers according to the rules and requirements set out in the regulations" (regulation of holding joint higher education courses in collaboration with foreign universities adopted on $6^{\text {th }}$ Oct., 2016). In this regard, the plans such as "ICARD" (International Cooperation for Applied Research Development), "ICAED" (International Cooperation for Applied Educational Development) and "ICED" (International Cooperation for Educational Development), facilitate the ground for this cooperation. The development of such plans is effective in advancing the internationalization of universities.

In Iran, in the area of academic scientific exchanges in various fields such as environment and Nano, there are some cooperation between Iranian universities and foreign universities and research centers and such cooperation has been developed recently so that in the months after Joint Comprehensive Plan of Action, some delegations from various countries have gone to Iran and signed Memorandum of Understandings for long-term plans with universities and research centers but these efforts are not enough, especially in the field of humanities (Zakerian, 1395). In fact, in the era of knowledge explosion where it is said that human knowledge doubles every five years, we cannot compete in the global science market with traditional sight and attitude and new approaches tailored to the needs of globalization must be taken (Fazli, Shams, 2004) to reach the level of scientific development where there is a possibility of communication with other universities and research centers. This 
communication is a way for dialogue and understanding and also a way to get acquainted with modern science and more scientific development.

One of the most important components should be considered in the pursuit of the goal of internationalization of universities, is academic freedom and independence. Independence reduces vulnerability of the university drastically so that it is not disturbed by changing a minister, political crises cannot be drawn to the universities, this independence increases academic stability and results in enhanced quality of university and universities become more specialized and more professional. The government can monitor as well as optimize the optimal production of knowledge. Only on the basis of independence, autonomy and academic freedom and independent professional management and through international free cooperation, university can take these missions and be responsive to community and it participates seriously and plays an effective role in eradicating poverty, illiteracy, hunger, social pathologies, anomie, alienation, fear and anxiety, disease, and enlightening the harmful effects of intolerance, violence and the deterioration of the environment and so on (Ferasatkhah, 2010). In Iran, the independence of universities has been not recognized and the facts on higher education indicate that the current centralized bureaucracy is not capable of leading higher education institutions. Higher education system as a sub-system of government and with a centralized structure on issues such as acceptance of student, curriculum, allocation of funds, the appointment of the chairman and the selection of university faculty members and staff, has lost its effectiveness (Arasteh, 2001). According to Nafisi's research, lack of academic independence and scientific freedom are of challenges that higher education system faces with them and due to the intense focus on higher education, university basically acts as an administrative unit (Nafisi, 2001) and if it acts in some limited areas independently (e.g. in the area of staff), it will be process instead of independence in planning and policy making areas.

\section{Discussion and conclusion}

In general, the university and the academic community can support the goals of foreign policy and diplomacy, especially during the cold political relations. So, Habermas's communicative action theory is a suitable framework for understanding how communication through university and higher education institution is effective in achieving mutual understanding, this communication is a free and rational action which is outside of power relations and formal interactions. The Islamic Republic of Iran does not neglect the importance of modern communications and new influential actors. Accordingly, in recent years, the role of the university in advancing the goals of foreign policy, as a rational agent in the diplomacy, has 
been noted and some measures have been taken to take advantage of the capacity of the institution especially in the form of policy of internationalization of universities by the Ministry of Science and other institutions. But, according to some researchers, Iranian universities cannot be known as international universities tailored to the international requirements. So, in addition to appropriate and purposeful policy-making, the conditions must be provided in order to realize international university and to use its capacity in the area of diplomacy. Recognizing the independence of universities, even if relatively, can enhance creativity and also, increase the ability of universities to risk. This independence should be recognized in all fields including research, content production, training and methods of delivery of content and applications and it is not that the program remains unresolved because of administrative process or it spend long process to be implemented.

About the discussion of internationalization at home, it is good to place new contents in the curriculum of students to introduce global requirements and issues and also to understand the importance of international communication and acceptance of diversity. The courses such as multiculturalism, peace, education, communication and dialogue can be effective in changing students' attitudes and as noted earlier, certain content should be produced in order to introduce Iranian-Islamic culture. Initiatives such as the establishment of the meetings on Persian Language, Islamic studies, Iranian studies can be evaluated in this direction. Training programs of universities, outside the curriculum, also is very effective in changing students' insight. Holding courses and workshops of crisis simulation and simulation of negotiations in order to understand the issues and to teach how to discuss, holding brainstorming and discussion sessions in the forms of liberal meetings and providing the ground for increased communication and interaction between students in different disciplines and different universities and new teaching methods such as class management in the form of meeting and conference can be effective in accelerating this process. Also, management structure of Iranian universities must be changed to provide the ground for creativity and innovation and to use others' experiences and comments.

About the international communication, there must be deep, purposeful and ongoing and not cross-sectional and short-term relationships with prestigious foreign universities and research centers. In this regard, Fathi Vajargah and et al. know the lack of ongoing relationship with the great universities in the world through exchange of professors and students as an obstacle to the internationalization of Iranian universities (Fathi Vajargah, 2009). So, the exact program is needed to identify prestigious centers and to communicate with them. In this regard, acceptance of student and professor needs to provide the requirements: from welfare 
conditions to educational facilities which are inadequate in Iran despite of many efforts and many non-Iranian students are complained of educational and welfare conditions (Yamani and Teimouri, 2015).

Also, a plan must be considered to enhance the English knowledge. In the discussion on the language, it should be noted that internationalization and international relationships have been linked with language skills. In Iranian universities, although there is a limited number of courses, many students and professors are not able to use language in order to communicate. This prevents the internationalization of the universities in Iran.

About sending student abroad, a coherent program should be considered by which the capacity of Iranian academics who are abroad, is used to create relationships between nations according to their cultural capacities. These people are great capital but according to the authorities of the Ministry of Science, there is no purposeful program to use their capacities in advancing the goals of foreign policy.

In the section of science and technology diplomacy, research activities of universities provide the ground of cooperation between academics and abroad research centers. In this regard, in recent years, many activities have been performed and these activities are developed and also qualitatively competitive. Especially, increased studies in the field of humanities with the aim of production of Iranian-Islamic views and vernacular literature would be effective. In Iran, the experiences show that although there has been no coherent and reliable process for this in recent years, sporadic experiments have been carried out in different institutions (VicePresidency for Science and Technology, Presidency of the Islamic Republic of Iran, 2011). And even the number of scientific advisors who can be effective in this communication is very low at about 6 people (official site of the Ministry of Science).

What seems to be important in the next step is the relationship between universities and diplomacy institution. The involvement of researchers and scientists in the field of foreign policy is very important so that it can promote the culture of peace and conversation. Some conditions must be provided for dialogue between policy makers, academics and researchers who work in the field of foreign policy and science to identify the trends which can provide the interests of the country better. Foreign policy institutions and thinking rooms can leads this communication. Also, informing diplomats and foreign policy system of the importance of science and technology is very important and an educational program must be considered to train diplomats and official authorities and to clarify the importance of science for political authorities. In this regard, the most important step may be the production of content in the academic and literature of science diplomacy. 
Last note is that using the experiences of other countries and organizing the activities based on successful experiences of other universities in the context of international communication is very effective. Today, many countries have realized the importance of science in advancing the goals of foreign policy and developed coherent programs. For example, Germany had followed the discussion of scientific and academic exchanges since 1925 and today, he has the largest scientific-academic exchanges institution called DAAD and/or Japan and India are two successful countries in the field of science diplomacy and China, England and Finland are successful countries in the internationalization of curriculum. They can be raised as a model for academic diplomacy in the Islamic Republic of Iran according to national and local conditions (Vice-Presidency for Science and Technology, Presidency of the Islamic Republic of Iran, 2011).

What should be considered is that university and activities in the field of science and technology that advancement of part of them is the task of universities, must be used as a tool to advance the goal of cooperation and dialogue and create a peaceful space and not as a tool for political interests that in this case, the end of science must be spoken (NAAAS, 2010). In the Islamic Republic of Iran, university can play an effective role in promoting the country's prestige in the international arena and provide the ground for communication and interaction by relying on science and the academic community. It must be noted that the success of these efforts depends on the purpose and acceptance of structures and international requirements.

So the promotion of university structures and mechanisms based on international standards, the adoption of policy of internationalization of universities and higher education institutions and in this context, the development of education and research in order to increase competitiveness and to attend in the international arena and above all, informing authorities of the importance of higher education institutions in advancing the goals of foreign policy, are the strategies to make maximum use of the capacity of higher education institutions in promoting a culture of peace in the international arena through establishing communication and dialogue.

\section{References}

1. (2010). New Frontiers in Science Diplomacy, NAAAS, The Royal Society. Available in:https://www.aaas.org/sites/default/files/New_Frontiers.pdf

2. (2011). Conceptual Study of science and technology diplomacy and outlining the current situation in the Islamic Republic of Iran, management summary of science and technology diplomacy, vice president of science and technology. 
3. Amacker, Christopher(2011). The Functions of Diplomacy, E-International Relations Studies, Available in: http://www.e-ir.info/2011/07/20/the-functions-of-diplomacy/

4. Arasteh, HR (2001). Leadership and management in universities: challenges and shortcomings, Journal of Research and Planning in Higher Education, Volume 7, Number 3 and 4.

5. Arefi, M. (2005). Strategic lesson planning in higher education, Tehran, Academic Center for Education, Culture and Research, Shahid Beheshti University.

6. Bilis, J. and Smith, S. (2004). Globalization policy: international relations in the new era (historical background, theories, structures and processes), translated by Rahchamani, A. et al., Tehran, Abrar-e Moaser Institute.

7. Bolton, Roger E(2016). A Comparison of a Habermas-Inspired Approach and Economists Approaches to Social Capital, NOV. 2014 North American Regional Science Conference Version. Available http://web.williams.edu/Economics/papers/Habermas.pdf.

8. De Wit, Hans, Hunter, Fiona, Howard, Laura, Egron-Polak, Eva (2015). Internationalisation of Higher Education, European Union. Available in: www.europarl.europa.eu/RegData/etudes/.../2015/.../IPOL_STU(2015)540370_EN.pd f.

9. Farasatkhah, M. (2010). How can we have high-quality universities?, Journal of Teaching Message, No. 8.

10. Fathi Vajargah, K., Yamani, M., Zare'e, A. (2009). Investigation of international barriers to curricula of universities and higher education institutions from the perspective of faculty members (Shahid Beheshti University), Journal of Research and Planning in Higher Education, Vol. 15, No. 4.

11. Fazeli, N. (2004). Review of globalization and global trends in higher education and status of higher education in Iran, Journal of Social Sciences, Allameh Tabatabai University, No. 25.

12. Fazli, N., Shams, N. (2004). Investigation of international scientific and academic exchanges and communication management system in Iran and Europe, Journal of Research and Planning in Higher Education, Vol. 10, No. 3.

13. Federoff, Nina(2010). Science Diplomacy in the 21st Century, Agricultural Outlook Forum U.S. Department of Agriculture. FOR ACTION, 1 July, Budapest.

14. Fitzpatrick, Kathy R(2011). U.S. PUBLIC DIPLOMACY IN A POST-9/11 WORLD: FROM 
https://uscpublicdiplomacy.org/sites/uscpublicdiplomacy.org/files/legacy/publications/ perspectives/CPDPerspectives_Mutuality.pdf

15. Gough, S. and Scott, W. (2007). Higher Education and Sustainable Development: Paradox and likely, translated by Ghorbani Sheikhneshin, Tehran, Institute of Social and Cultural Studies.

16. Griffiths, M. (2009). Encyclopedia of international relations and global politics, translated by Tayyeb, A., Tehran, Nei Press.

17. Hadian, N., Saeidi, R. (2013). From traditional public diplomacy to new public diplomacy: Habermasian approach, Journal of strategy, No. 68.

18. http://www.msrt.ir/ (Official website of the Ministry of Science, Research and Technology)

19. Jonstone, Ian(2003). Security Council Deliberations: The Power of the better Argument, EJIL, Vol 14, No 3.

20. Knight, J.(2008). Higher education in turmoil:The changing world of internationalization. Rotterdam, the Netherlands, Sense Publishers.

21. Mahdavi, MS., Mobaraki, M. (2006). Analysis of Habermas's communicative action theory, Journal of Social Sciences, Islamic Azad University, Khalkhal, No. 8.

22. Mahozi, R. (2016). Social and cultural dimensions of internationalization of universities (the situation in Iran and the international experience), Tehran, Institute of Social and Cultural Studies.

23. Maringe,F\& Foskett, Nick(2010). Globalization and internationalization in higher education .Theoretical, Strategic and Management Perspectives,_London, Continuum.

24. Mir, I. (2007). Towards a comprehensive theory in Habermas's thought, Karaj Islamic Azad University, Quarterly of Political Science, Issue 7.

25. Moshirzadeh, H. (2005). Changes in international relations theories, Tehran, Samt Press

26. Nafisi, A. (2001). Analysis of higher education system in Iran, Institute for Research and Planning in Higher Education (combined report, No.6).

27. Nye, Joseph S (1990). Soft Power, Foreign Policy, No 80.

28. Official website of Center for Scienctific and International Cooperation, Available in: http://www.cissc.ir/

29. Reardon, B (1988). Comprehensive Peace Education, NY: Teachers College Press.

30. Risse, Thomas (2000). Let,s Argue: Communicative Action in World Politics, International Organization, Vol. 54, No. 1. 
31. Ritrez, G. (2009). Sociological theory in modern times, translated by Salasi, A., Tehran, Elmi Press.

32. Shah Talebi, B. (2008). Recognition of the important characteristics of the third millennium universities to provide a suitable framework for universities in Iran in order to move from traditional university to modern universities, Journal of Education, Volume 4, Issue 16.

33. The Ministry of Science, Research and Technology (2012), regulation of holding joint higher education courses in collaboration with foreign universities adopted on $6^{\text {th }}$ Oct., 2016

34. Turekian, Vaughan C. \& Neureiter, Norman P(2012). Science and Diplomacy: The Past as Prologue, Available in: http://www.sciencediplomacy.org/editorial/2012/science-and-diplomacy

35. World Conference on Science(1999). SCIENCE AGENDA-FRAMEWORK. Available in: www.unesco.org/science/wcs/eng/framework.html

36. Yamanidouzi Sorkhabi, M., Teimouri, M. (2015). The academic living conditions of students studying in public universities in Iran in the academic year 2013-14, Journal of Iran Higher Education Association, the seventh year, No.2.

37. Zakerian, M. (2016). The science diplomacy or diplomacy Track II, interview

\section{How to cite this article:}

Zakerian M, Sadoughi Z, Nabavi A, Mahdi R. Realization of peace from the perspective of the role of higher education in the field of diplomacy: experience of academic diplomacy in iran. J. Fundam. Appl. Sci., 2016, 9(1S), 184-203. 